\title{
Use of Subcutaneous Port Catheter in Childhood Malignancies
}

\author{
Onur Doyurgan1*, Uğur Karagöz¹, Bengü Demirağ2, Mustafa Karaçelik¹, Yılmaz Ay², \\ Raziye Canan Vergin ${ }^{2}$, Osman Nejat Sarısmanoğlu1 \\ ${ }^{1}$ Department of Pediatric Cardiac Surgery, Dr. Behçet Uz Children's Hospital, Izmir, Turkey \\ ${ }^{2}$ Department of Pediatric Hematology-Oncology, Dr. Behçet Uz Children's Hospital, Izmir, Turkey \\ Email: *onurdoyurgan@gmail.com,drugurk@hotmail.com,drbdemirag@hotmail.com, \\ mkaracelik@hotmail.com,dryilmazay@yahoo.com,cvergin@gmail.com,dronsar@yahoo.com
}

Received 29 March 2016; accepted 17 May 2016; published 20 May 2016

Copyright (C) 2016 by authors and Scientific Research Publishing Inc.

This work is licensed under the Creative Commons Attribution International License (CC BY).

http://creativecommons.org/licenses/by/4.0/

(c) () Open Access

\section{Abstract}

Background: The port catheters are used to give long-term total parenteral nutrition, intravenous fluids, blood and blood products, or to be preferred for oncology and hematological diseases. In this study, we sought to review our results concerning the subcutaneous port catheter appliance in childhood malignancies. Methods: Two hundred ten subcutaneous port catheters applied to 192 patients between November 2010 and October 2015 were examined retrospectively in a crosssectional study. Information such as demographic data, primary diagnoses, port types and implantation durations were recorded. Localization of the intervention, surgical technique, early and late complications and causes of port removal were evaluated. Results: Mean age of patients was $6.4 \pm 4.9$ years (1 month - 17 years), $77(40.1 \%)$ were female and $115(59.9 \%)$ male. One hundred twenty nine ports were inserted from the right internal jugular vein, 59 to right subclavian vein, 14 to left subclavian vein and 8 to left internal jugular vein. Total duration of implantation was 55,492 days and median duration was 289 days. Early complications were: $1(0.5 \%)$ hemothorax, $1(0.5 \%)$ pneumothorax, $1(0.5 \%)$ carotid artery injury, $1(0.5 \%)$ arrhythmia and in $2(1 \%)$ cases port mal-positioning. Late complications were: $9(4.3 \%)$ infection and $8(3.8 \%)$ mechanical problems, $7(3.3 \%)$ thrombosis, and in $1(0.5 \%)$ port fracture was detected. Port catheter was removed in $18(8.6 \%)$ cases. No significant difference was found when jugular and subclavian vein implantation was compared in terms of all complications, especially infection and thrombosis. Conclusion: Use of port catheter is a safe option in children who are receiving a long-term chemotherapy. Education of the medical team will diminish the complication rate in port catheter insertions.

\section{Keywords}

Port Catheters, Childhood Malignancy, Postoperative Complications

\footnotetext{
*Corresponding author.
}

How to cite this paper: Doyurgan, O., Karagöz, U., Demirağ, B., Karaçelik, M., Ay, Y., Vergin, R.C. and Sarıosmanoğlu, O.N. (2016) Use of Subcutaneous Port Catheter in Childhood Malignancies. World Journal of Cardiovascular Diseases, 6, $126-132$. http://dx.doi.org/10.4236/wjcd.2016.65013 


\section{Introduction}

The introduction of totally implantable devices started in the 1980s. Since none of their parts are outside the body, port catheters allow freedom of movement during daily activities in the children, and therefore they are more convenient and the infection incidence is lower as compared to non-totally implantable devices [1]. The port catheters are used to give long-term total parenteral nutrition, intravenous fluids, blood and blood products, or to be preferred for oncology and hematological diseases [2]. However, several complications may occur during their use and insertion [3] [4]. Infection and thrombosis are the most common complications [5] [6]. The complications increase the hospitalization period, hospital costs, morbidity and mortality. In this study, we sought to review our results concerning the subcutaneous port catheter appliance in childhood malignancies.

\section{Methods}

\subsection{Patient Population}

In this cross-sectional study, between November 2010 and October 2015, hospital records of 192 children who hadmalignity and port catheters were assessed retrospectively in the departments of hematology/oncology and pediatric cardiovascular surgery, Izmir Dr. Behçet Uz Children's Hospital. The demographical data, primary diagnosis, duration of port insertion period (port day), size and type of the port (Table $1 \&$ Table 2), the inserted vessel, insertion method, problems during insertion, early and delayed complications associated with the port, and the reasons of removing ports were recorded. The complications during in first 24 hours were classified as early complications. After 24 hours, it was classified as delayed complications. Izmir Dr. Behçet Uz Children's Hospital's Ethics Committee approval on 20/11/2016 gave permission for review of medical records on 18/01/ 2016 (ref: 2016/01-03).

\subsection{Surgical Process}

After having informed consent, under general anesthesia, electrocardiography (ECG), peripheral oxygen saturation $\left(\mathrm{SpO}_{2}\right)$ and blood pressure were measured. In supine position, following venous puncture, using Seldinger technique, if extra-systole was observed in ECG, the guide wire was drawn back to the level without extra-systole. The vessel dilator and its sheath were placed into the vessel. To insert the port body, a $3 \mathrm{~cm}$ incision was made at the 3rd intercostal space level, and a port pocket was formed. The port catheter was pushed forward to the puncture site with a tunnel opener rod. The port body was fixed under the skin with a 4/0 polyglactin 910 suture. The port reservoir was washed out with $100 \mathrm{U} / \mathrm{ml}$ heparinized fluids. Posterior-anterior chest radiography was performed for all patients in the same day to check the place of the port and to see whether there is hemothorax or pneumothorax.

\subsection{Follow-Up}

All wounds were dressed every day till discharge. All patients were followed up at every outpatient visit till the removal of port catheter. In the remission patients whose chemotherapy completed, the port catheters were washed out with saline solution, once every three months and closed with heparinized fluid. If optimal treatment response was not obtained in the patients who hospitalized due to complications during follow-up period, the port was removed. A new port catheter was inserted in the contralateral side in the patients whose chemotherapy would continue.

Table 1. Demographic data of patients.

\begin{tabular}{ccc}
\hline & $\mathbf{n}$ & $\%$ \\
\hline Sex & 77 & \\
Female & 115 & 40.1 \\
Male & 69.9 \\
Age & $6.49(1$ month - 17 years $)$ & \\
\hline
\end{tabular}


Table 2. Types and characteristics of the port catheter.

\begin{tabular}{|c|c|c|}
\hline & $\mathbf{n}$ & $\%$ \\
\hline \multicolumn{3}{|l|}{ Port type } \\
\hline PEROUSE MEDICAL Polysite ${ }^{\circledR}$ & 108 & 51.4 \\
\hline MEDCOMP Pro-Fuse ${ }^{\circledR C T}$ & 89 & 42.3 \\
\hline BRAUN Celsite ${ }^{\circledR B a b y}$ & 7 & 3.4 \\
\hline FB MEDICAL IN-PORT® & 6 & 2.9 \\
\hline \multicolumn{3}{|l|}{ Catheter size } \\
\hline $4 \mathrm{Fr}$ & 34 & 16.2 \\
\hline $5 \mathrm{Fr}$ & 91 & 43.3 \\
\hline $6 \mathrm{Fr}$ & 49 & 23.4 \\
\hline $7 \mathrm{Fr}$ & 36 & 17.1 \\
\hline \multicolumn{3}{|l|}{ Insertion site } \\
\hline Right internal jugular vein & 129 & 61.4 \\
\hline Right subclavian vein & 59 & 28.1 \\
\hline Left subclavian vein & 14 & 6.7 \\
\hline Left internal jugular vein & 8 & 3.8 \\
\hline \multicolumn{3}{|l|}{ Port days } \\
\hline Total & 55,492 & \\
\hline Mean & 289 & \\
\hline Median & $8-937$ & \\
\hline
\end{tabular}

\subsection{Definition of Infection}

Infection is defined as follows: bacteria presence on catheter surface without the clinical signs of inflammation or bacteremia, local infection signs on catheter insertion site without systemic infection, the identification of the same microorganism growth in blood cultures drew simultaneously from peripheral vessels and catheter, septic thrombophlebitis [7].

\subsection{Statistical Analysis}

Statistical analysis of the data was performed with SPSS 17.0 (SPSS Inc., Chicago, IL, USA) program. Kolmogorov-Simonov test was used to analyze distribution normality of the numeric data. Chi-square test was used to compare categorical data. $P<0.05$ was considered as statistically significant.

\section{Results}

In cardiovascular surgery clinic, total of 210 subcutaneous port catheters were inserted to 192 patients between November 2010 and October 2015. The average age of the patients was $6.4 \pm 4.9$ year (1 month - 17 years) and $77(40.1 \%)$ of them were female and 115 (59.9\%) of them were male. The demographical data, types and characteristics of the port catheters were summarized in Table $1 \&$ Table 2. The distribution of cases by diagnosis according to International Pediatric Cancer Classification (ICCC, 1996) was presented in Table 3 [8]. Two hundred ten cases, the following veins were used for port catheter insertion: 129 (61.4\%) to right internal jugular, 59 (28.1\%) to right subclavian, 14 (6.7\%) to left subclavian and 8 (3.8\%) to left internal jugular. Three cases had 3 times port catheter insertions (1.4\%), 12 cases (5.7\%) had twice. Total port day was 55,492 days and mean port day was 289 days. The early complications were as follows: $1(0.5 \%)$ hemothorax, $1(0.5 \%)$ pneumothorax, 1 (0.5\%) carotid artery injury, $1(0.5 \%)$ arrhythmia, and $2(1 \%)$ malposition. The late complications as follows: 9 (4.3\%) infections, 7 (3.3\%) port thromboses and $1(0.5 \%)$ port fracture. No significant difference was found 
Table 3. The distribution of cases by diagnosis according to international classification of childhood cancer (ICCC 1996).

\begin{tabular}{|c|c|c|}
\hline Diagnosis & Cases & $\%$ \\
\hline 1. Leukemia & 106 & 55.2 \\
\hline 2. Lymphomas & 14 & 7.3 \\
\hline 3. Brain and spinal tumors & 12 & 6.2 \\
\hline 4. The sympathetic system tumors & 15 & 7.8 \\
\hline 5. Retinoblastoma & 5 & 2.6 \\
\hline 6. Kidney tumors & 7 & 3.6 \\
\hline 7. Liver tumors & 3 & 1.6 \\
\hline 8. Bone tumors & 20 & 10.4 \\
\hline 9. Soft tissue sarcomas & 3 & 1.6 \\
\hline 10. Gonads and germ cell tumors & 1 & 10.4 \\
\hline 11. Epithelial tumors & 3 & 1.6 \\
\hline $\begin{array}{l}\text { 12. Other tumors (hemophagocytic lymphoma, } \\
\text { histiocytosis, langerhans cell histiocytosis) }\end{array}$ & 3 & 1.6 \\
\hline Total & 192 & 100 \\
\hline
\end{tabular}

when jugular and subclavian vein implantation was compared in terms of all complications, especially infection and thrombosis.

\section{Discussion}

Cephalic, internal jugular, subclavian or lower extremity veins may be used for catheterization. Subclavian vein is preferred due to the short distance to the vena cava superior. However, a puncture in this vein has higher risk of pneumothorax [9] [10]. In a meta-analyze, compared the complication incidence of jugular and subclavian catheter insertion, infection and artery injury complications were higher in the internal jugular insertions, and hemo-pneumothorax and malposition complications were higher in the subclavian insertions. In our study, internal jugular vein was chosen in 65.2\% $(n=137)$ cases, subclavian vein was chosen in $34.8 \%(n=73)$ cases and 23 cases (10.9\%) had complications (Table 4). Four (6.6\%) of them were to jugular, and $9(4.3 \%)$ of them to subclavian insertion. Pneumothorax $(n=1)$, hemothorax $(n=1)$, carotid artery injury $(n=1)$ and malposition $(n=2)$ were observed following jugular port implantation; arrhythmia $(n=1)$ was observed following subclavian port implantation. Infection $(P=0.722)$ and thrombosis $(P=0.24)$ No statistical significant differences were found between jugular and subclavian insertions in terms of development.

Right atrium and superior vena cava junction is the best site for the port tip. If port catheter tip is not localized close to here, it is defined as a catheter malposition [11]-[13]. We detected in our 2 patients (1\%) after the port insertion to right internal jugular vein showed that the tip of port catheter is inserted right subclavian vein instead of cava-atrial junction. A guide wire was pushed forward on port by scope in these patients. The port catheter was drawn back and was directed to superior vena cava. Besides, if the catheter tip is moved into right ventricle or inferior vena cava, arrhythmia may occur [14]. The arrhythmia was observed during follow-up in a patient whom had been inserted from right internal jugular vein. The echocardiography showed the port tip was in the right ventricle wall. The port was drawn back by scope and turned down and pushed forward to the cava-atrial junction. We don't use scope for port catheter insertion routinely in our clinic.

We detected the incidence of infection induced by port insertion ranges between 0.8 - 7.5 percent [15] [16]. In oncology patients, the infection incidence of port catheters is lower than tunneled catheters [17]. The infection is commonly caused by Staphylococcus epidermidis or aureus and Candida albicans [18] [19]. However port systems must be removed in case of persistent sepsis/bacteremia or relapse of infection after antibiotic treatment, signs of port or catheter tunnel infection, unstable patients (port infection and hypotension), systemic complications (e.g. septic thrombosis/embolism, osteomyelitis, abscess formation or endocarditis) or detection of certain 
microorganisms such as S. aureus or Candida species [20]-[22]. Port catheter was removed from total of 18 (8.6\%) patients (Table 5). Nine patients (4.3\%) whose port was removed due to infection had the local signs of inflammation and 4 of them (1.9\%) had positive blood culture for Candida albicans proliferation. In these cases, a new port catheter was placed to the contralateral side after removing port removal immediately. Another major long-term complication is port thrombosis [23]. In the cancer patients, the incidence of catheter-induced thrombosis was 3\% - 4\% in several studies [24]. Avoiding from this complication, port care is important. Cancer Care Ontario guideline is accepted as a care guide [25]. Compatible with the literature, the incidence of port catheter thrombosis was 3.3\% $(n=7)$ in our study. "Pinch off" syndrome is defined as a port catheter fracture due to compression between the clavicle and first costae, leading to pain under clavicle, paresthaesia in arm, subdermal fluid extravasations, pain in arm, and ubdermal necrosis [26] [27]. In our case, subdermal fluid collection and fluid extravasations during infusion was identified 148 days after the port catheter insertion. Catheter fracture was identified and then port catheter was removed, a new port catheter was implanted to the contralateral side. Carotid artery injury during central venous catheterization could lead to catastrophic serious complications. In some studies, the incidence of carotid artery injury was especially higher in the infants younger than 6 months [28]-[30]. In a patient who had been inserted to right subclavian vein, the port catheter was in the right subclavian artery. Right subclavian artery and catheter were explored, and then catheter was drawn back and the vessel was repaired primarily.

\section{Study Limitations}

Our study, as with all cross-sectional studies, was limited by follow-up data quality, availability and interpretation. Non-homogenous patient population led to another difficulty of statistical analysis. Therefore, we tried to

\begin{tabular}{|c|c|c|c|c|}
\hline & Internal jugular & Subclavian & Pvalue & Total \\
\hline \multicolumn{5}{|l|}{ Early complications } \\
\hline Pneumothorax & 1 & 0 & & 1 \\
\hline Hemothorax & 1 & 0 & & 1 \\
\hline Carotid artery injury & 1 & 0 & & 1 \\
\hline Malposition & 2 & 0 & & 2 \\
\hline Arrhythmias & 0 & 1 & & 1 \\
\hline \multicolumn{5}{|l|}{ Late complications } \\
\hline Infection & 5 & 4 & 0.722 & 9 \\
\hline \multicolumn{5}{|l|}{ Mechanical problems } \\
\hline -Thrombosis & 3 & 4 & 0.24 & 7 \\
\hline -Breaking & 1 & 0 & & 1 \\
\hline Total & 14 & 9 & 0.648 & 23 \\
\hline
\end{tabular}

\begin{tabular}{ccc}
\hline Table 5. Subcutaneous port catheter removal reasons. & \\
\hline & $\mathrm{n}$ & $\%$ \\
\hline Infection & 9 & 4.3 \\
Mechanical problems & & 3.3 \\
Thrombosis & 7 & 0.5 \\
Breaking & 1 & 0.5 \\
Carotid artery injury & 1 & 8.6 \\
\hline Total & 18 & \\
\hline
\end{tabular}


reflect the real-life data all we had.

In conclusion, despite the higher risk of complications, subcutaneous port catheter implantation was the gold standard for the treatment of pediatric malignancies. The increased use of subcutaneous port catheters increased the incidence of catheter-induced complications. The experience was very important to prevent these complications. We believed that the incidence of the complications related with subcutaneous port catheter would decrease if the doctor, nurse and patient's family got more knowledge.

\section{Acknowledgements}

We wish to thank Assoc. Prof. Murat Muhtar Yilmazer, M.D. in Department of Pediatric Cardiology, Dr. Behçet Uz Children's Hospital, for help on statistical analysis. The authors received no financial support for the research and/or authorship of this article. The authors declare that they have no conflict of interests.

\section{References}

[1] Ross, M.N., Haase, G.M., Poole, M.A., Burrington, J.D. and Odom, L.F. (1998) Comparison of Totally Implanted Reservoirs with External Catheters as Venous Access Devices in Pediatric Oncologic Patients. Surgery, Gynecology \& Obstetrics, 167, 141-144.

[2] Mirro Jr., J., Rao, B.N., Stokes, D.C., et al. (1989) A Prospective Study of Hickman/Broviac Catheters and Implantable Ports in Pediatric Oncology Patients. Journal of Clinical Oncology, 7, 214-222.

[3] de Jonge, R.C., Polderman, K.H. and Gemke, R.J. (2005) Central Venous Catheter Use in the Pediatric Patient: Mechanical and Infectious Complications. Pediatric Critical Care Medicine, 6, 329-339. http://dx.doi.org/10.1097/01.PCC.0000161074.94315.0A

[4] Kock, H.J., Pietsch, M., Krause, U., Wilke, H. and Eigler, F.W. (1998) Implantable Vascular Access Systems: Experience in 1500 Patients with Totally Implanted Central Venous Port Systems. World Journal of Surgery, 22, 12-16. http://dx.doi.org/10.1007/s002689900342

[5] Biffi, R., Orsi, F., Pozzi, S., et al. (2009) Best Choice of Central venous Insertion Site for the Prevention of Catheter-Related Complications in Adult Patients Who Need Cancer Therapy: A Randomized Trial. Annals of Oncology, 20, 935-940. http://dx.doi.org/10.1093/annonc/mdn701

[6] Ingram, J., Weitzman, S., Greenberg, M.L., Parkin, P. and Filler, R. (1991) Complications of Indwelling Venous Access Lines in the Pediatric Hematology Patient: A Prospective Comparison of External Venous Catheters and Subcutaneous Ports. The American Journal of Pediatric Hematology/Oncology, 13, 130-136. http://dx.doi.org/10.1097/00043426-199122000-00003

[7] Vescia, S., Baumgärtner, A.K., Jacobs, V.R., et al. (2008) Management of Venous Port Systems in Oncology: A Review of Current Evidence. Annals of Oncology, 19, 9-15. http://dx.doi.org/10.1093/annonc/mdm272

[8] Steliorova-Foucher, E., Stiller, C., Lacour, B., et al. (2005) International Classification of Childhood Cancer. Cancer, 103, 1457-1467. http://dx.doi.org/10.1002/cncr.20910

[9] Cowl, C.T., Weinstock, J.V., Al-Jurf, A., Ephgrave, K., Murray, J.A. and Dillon, K. (2000) Complications and Cost Associated with Parenteral Nutrition Delivered to Hospitalized Patients through Either Subclavian or Peripherally-Inserted Central Catheters. Clinical Nutrition, 19, 237-243. http://dx.doi.org/10.1054/clnu.2000.0103

[10] Özer, A.B. and Bayar, M.K. (2011) Implante Edilebilir Venöz Port Kateter Uygulamalarımızın İncelenmesi. Firat Tip Dergisi, 16, 6-10.

[11] Babu, R. and Spicer, R.D. (2002) Implanted Vascular Access Devices (Ports) in Children: Complications and Their Prevention. Pediatric Surgery International, 18, 50-53. http://dx.doi.org/10.1007/s003830200011

[12] Lorenz, J.M., Funaki, B., Van Ha, T. and Leef, J.A. (2001) Radiologic Placement of Implantable Chest Ports in Pediatric Patients. American Journal of Roentgenology, 176, 991-994. http://dx.doi.org/10.2214/ajr.176.4.1760991

[13] Glaser, D.W., Medeiros, D., Rollins, N. and Buchanan, G.R. (2001) Catheter-Related Thrombosis in Children with Cancer. Journal of Pediatrics, 138, 255-259. http://dx.doi.org/10.1067/mpd.2001.111272

[14] Hacking, M.B., Brown, J. and Chisholm, D.G. (2003) Position Dependent Ventricular Tachycardia in Two Children with Peripherally Inserted Central Catheters (PICCs). Pediatric Anesthesia, 13, 527-529. http://dx.doi.org/10.1046/j.1460-9592.2003.01021.x

[15] Groeger, J.S., Lucas, A.B., Thaler, H.T., et al. (1993) Infectious Morbidity Associated with Long-Term Use of Venous Access Devices in Patients with Cancer. Annals of Internal Medicine, 119, 1168-1174. http://dx.doi.org/10.7326/0003-4819-119-12-199312150-00003

[16] Teichgräber, U.K., Pfitzmann, R. and Hofmann, H.A. (2011) Central Venous Port Systems as an Integral Part of Che- 
motherapy. Deutsches Ärzteblatt International, 108, 147-153.

[17] Graham, D.R., Keldermans, M.M., Klemm, L.W., Semenza, N.J. and Shafer, M.L. (1991) Infectious Complications among Patients Receiving Home Intravenous Therapy with Peripheral, Central, or Peripherally Placed Central Venous Catheters. The American Journal of Medicine, 91, 95-100. http://dx.doi.org/10.1016/0002-9343(91)90351-W

[18] Yildizeli, B., Laçin, T., Batirel, H.F. and Yüksel, M. (2004) Complications and Management of Long-Term Central Venous Access Catheters and Ports. The Journal of Vascular Access, 5, 174-178.

[19] Fätkenheur, G., Buchheidt, D., Cornely, O.A., et al. (2003) Infectious Diseases Working Party (AGIHO) of the German Society of Hematology and Oncology (DGHO): Central Venous Catheter (CVC)-Related Infections in Neutropenic Patients. Annals of Hematology, 82, S149-S157. http://dx.doi.org/10.1007/s00277-003-0769-z

[20] Hengartner, H., Berger, C., Nadal, D., Niggli, F.K. and Grotzer, M.A. (2004) Port-A-Cath Infections in Children with Cancer. European Journal of Cancer, 40, 2452-2458. http://dx.doi.org/10.1016/j.ejca.2004.07.017

[21] O’Grady, N.P., Alexander, M., Burns, L.A., et al. (2011) Guidelines for the Prevention of Intravascular Catheter-Related Infections. American Journal of Infection Control, 39, S1-S34. http://dx.doi.org/10.1016/j.ajic.2011.01.003

[22] Bouza, E., Burillo, A. and Munoz, P. (2002) Catheter-Related Infections: Diagnosis and Intravascular Treatment. Clinical Microbiology and Infection, 8, 265-274. http://dx.doi.org/10.1046/j.1469-0691.2002.00385.x

[23] Sutherland, D.E., Weitz, I.C. and Liebman, H.A. (2003) Thromboembolic Complications of Cancer: Epidemiology, Pathogenesis, Diagnosis and Treatment. American Journal of Hematology, 72, 43-52. http://dx.doi.org/10.1002/ajh.10263

[24] Wiegering, V., Schmid, S., Andres, O., et al. (2014) Thrombosis as a Complication of Central Venous Access in Pediatric Patients with Malignancies: A 5-Year Single-Center Experience. BMC Hematology, 14, 18. http://dx.doi.org/10.1186/2052-1839-14-18

[25] Green, E., Macartney, G., Zwaal, C., et al. (2008) Managing Central Venous Access Devices in Cancer Patients: A Practice Guideline. Canadian Oncology Nursing Journal, 18.

[26] Lin, C.H., Wu, H.S., Chan, D.C., Hsieh, C.B., Huang, M.H. and Yu, J.C. (2010) The Mechanism of Failure of Totally Implantable Central Venous Access System: Analysis of 73 Cases with Fracture of Catheter. European Journal of Surgical Oncology, 36, 100-103. http://dx.doi.org/10.1016/j.ejso.2009.07.011

[27] Kurul, S., Saip, P. and Aydin, T. (2002) Totally Implantable Venous-Access Ports: Local Problems and Extravasation Injury. The Lancet Oncology, 3, 684-692. http://dx.doi.org/10.1016/S1470-2045(02)00905-1

[28] Hayashi, Y., Uchida, O., Takaki, O., et al. (1992) Internal Jugular Vein Catheterization in Infants Undergoing Cardiovascular Surgery: An Analysis of the Factors Influencing Successful Catheterization. Anesthesia \& Analgesia, 74, 688-693. http://dx.doi.org/10.1213/00000539-199205000-00012

[29] Verghese, S.T., Patel, R.I. and Hannallah, R.S. (1993) Central Venous Cannulation in Infants and Children: A Comparison of Internal and External Jugular Vein Approaches. Pediatric Anesthesia, 3, 95-99. http://dx.doi.org/10.1111/j.1460-9592.1993.tb00044.x

[30] Ruesch, S., Walder, B. and Tramèr, M.R. (2002) Complications of Central Venous Catheters: Internal Jugular versus Subclavian Access-A Systematic Review. Critical Care Medicine, 30, 454-460.

http://dx.doi.org/10.1097/00003246-200202000-00031 